\title{
Smoking and outcomes in kidney transplant recipients: a post hoc survival analysis of the FAVORIT trial
}

\author{
Larry A Weinrauch ${ }^{1-4}$ \\ Brian Claggett ${ }^{1,4}$ \\ Jiankang Liu' \\ Peter V Finn' \\ Matthew R Weir ${ }^{5}$ \\ Daniel E Weiner ${ }^{6}$ \\ John A D’Elia ${ }^{2-4}$ \\ 'Cardiovascular Division, Brigham \\ and Women's Hospital, ${ }^{2}$ Kidney and \\ Hypertension Section, Joslin Diabetes \\ Center, ${ }^{3}$ Department of Medicine, \\ Beth Israel Deaconess Hospital, \\ ${ }^{4}$ Harvard Medical School, Boston, MA, \\ ${ }^{5}$ Division of Nephrology, Department \\ of Medicine, University of Maryland, \\ College Park, MD, ${ }^{6}$ Division of \\ Nephrology, Tufts University School of \\ Medicine, Boston, MA, USA
}

Correspondence: Larry A Weinrauch 521 Mount Auburn Street, Watertown, MA 02472, USA

$\mathrm{Tel}+\mathrm{I} 6179230800$

Email Iweinrauch@hms.harvard.edu
This article was published in the following Dove Press journal: International Journal of Nephrology and Renovascular Disease

Background: Tobacco use remains an international health problem with between $10 \%$ and $40 \%$ of adults currently using tobacco. Given the rising number of patients either awaiting or having received a kidney transplant and the absence of smoking cessation as the criterion for transplantation in guidelines, we explored the association between smoking status and clinical outcomes in kidney transplant recipients.

Patients and methods: In this post hoc analysis of the Folic Acid for Vascular Outcome Reduction in Transplant trial, the associations between smoking status, defined as never having smoked, formerly or currently smoking, and both all-cause mortality and graft survival were assessed using Cox proportional hazards models. Fatal events were centrally adjudicated into prespecified categories: all-cause, cardiovascular and non-cardiovascular causes. Graft loss was defined as return to dialysis or retransplantation. Clinical Trials URL: http:/www.clinicaltrials.gov/show/NCT00064753. Results: Among 4110 transplant recipients, there were 451 current smokers and 1611 former smokers. The mortality rate per 100 patient-years was 4.0 (71 deaths) for smokers, 3.5 (226 deaths) for former smokers and 2.4 (116 deaths) for never smokers. Hazard ratio for mortality for current smokers was $1.70(\mathrm{CI}=1.26-2.29, p=0.001)$ and for former smokers was 1.21 $(0.98-1.50, p=0.08)$ with 1.0 representing never smokers. As the number of cardiovascular deaths was similar in each group (all $p>0.3$ ), the differences between groups was driven by non-cardiovascular death rates. Current smokers $(2.39 ; 1.62-3.61, p<0.001)$ and former smokers $(1.50 ; 1.12-2.01, p=0.007)$ had increased hazard of non-cardiovascular death. Kidney allograft failure was more likely in current smokers than in either former or never smokers $(3.5,2.1$ and 2.0 per 100 patient-years, $p<0.001$, adjusted hazard ratio 1.49 and 1.05 , respectively).

Conclusion: Continued smoking was associated with $>100 \%$ increased risk of non-cardiovascular death, $70 \%$ greater risk of all-cause mortality and a 50\% greater risk of graft loss, a risk not seen in former smokers. These findings confirm previous non-adjudicated observations that smoking is associated with adverse clinical outcomes and suggest that more emphasis should be placed on smoking cessation prior to kidney transplantation.

Keywords: tobacco, infection, infectious death, transplant loss, graft loss, non-cardiovascular mortality, diabetes

\section{Plain language summary}

Question? Does continued smoking impact patient and graft survival after kidney transplantation?

What were the findings? Analysis of centrally adjudicated survival data from 4110 stable kidney transplant recipients followed for an average of 4 years demonstrates that $11 \%$ were currently smoking, 39\% former smokers, 50\% never smoked. Continued smoking was associated 
with marked increases in the risk of all cause and non-cardiovascular mortality as well as a $50 \%$ greater risk of graft loss when compared to non-smokers and those who have ceased to smoke. Current smoking was associated with $100 \%$ increase in hazard of noncardiovascular death, 50\% increase in allograft failure and $60 \%$ increase in composite end-point of death or allograft failure.

What is the meaning of these findings? These findings confirm prior, non-adjudicated observations and suggest that more emphasis should be placed on smoking cessation in kidney transplant recipients. Cessation of smoking is needed in kidney transplants recipients to preserve survival free of dialysis

\section{Background}

Chronic tobacco use is associated with suppression of immune recognition, stimulation of platelet activation and enhancement of vascular tone. Exposure to tobacco increases perioperative cardiovascular and pulmonary complications. It is currently accepted that transplant of lungs, heart or liver cannot be considered without smoking cessation. ${ }^{1-4}$ Guidelines for kidney transplantation, however, do not require smoking cessation despite the risk of neoplasia with immunosuppression. ${ }^{5,6}$ Reviews of dialysis populations demonstrate that the prevalence of current smoking exceeds $10 \%$ and is much higher in certain geographic areas. ${ }^{7,8}$ In the Folic Acid for Vascular Outcome Reduction in Transplant (FAVORIT) trial, which included stable kidney transplant recipients in Canada, the USA and Brazil and was one of the largest trials involving clinically stable kidney transplant recipients, we observed that $11 \%$ of patients continued to smoke. ${ }^{9-11}$

Recent studies have suggested that smoking cessation may improve transplant allograft success. Accordingly, we explored whether smoking adversely effects both kidney transplant recipient and allograft survival after successful kidney transplantation. A secondary hypothesis was that the prevalence of smoking might have different impact on clinical outcomes in relation to the absence, or presence and type of diabetes.

\section{Patients and methods}

This is a post hoc analysis of the international FAVORIT trial. The FAVORIT enrolled 4110 transplant recipients who had received kidney allografts at least 6 months previously with stable graft function but elevated plasma homocysteine levels. Exclusion criteria included associated comorbidities that could be expected to limit survival (cancer, end-stage human immunodeficiency virus, hepatic pulmonary or cardiac disease) as well as recent ( $<3$ months) cardiovascular and kidney events or surgical procedures. The completed study did not demonstrate a reduction in cardiovascular endpoints using a combination of vitamins B6, B12 and folic acid, compared to placebo. The complete methods and results of this trial are reported elsewhere. $^{9-11}$ Enrollment occurred at 27 clinical sites in Brazil, Canada and the USA between August 2002 and January 2007. All enrollees were between 35 and 75 years of age with elevated homocysteine levels ( $>11 \mathrm{~mol} / \mathrm{L}$ for women, $>12 \mathrm{~mol} / \mathrm{L}$ for men). Follow-up contacts occurred every 6 months through January 31,2010 , to obtain study-related outcomes through June 24, 2009. The trial received approval from the institutional review or ethics boards of all clinical sites. Written informed consent was obtained from all participants.

Participants self-identified as never having smoked, ever having smoked but quit and currently smoking. Other key baseline data included diabetes status defined by analysis of data including use of insulin before age 40. Prescription medications taken regularly during the previous month were recorded during participant interviews.

History of cardiovascular events included the following: myocardial infarction or coronary artery revascularization (i.e., coronary artery bypass surgery or angioplasty), stroke (thromboembolic or hemorrhagic), carotid arterial revascularization (endarterectomy or angioplasty), abdominal or thoracic aortic aneurysm repair, renal arterial revascularization (bypass surgery or angioplasty), lower extremity arterial revascularization (bypass surgery or angioplasty) or lower extremity amputation above the ankle.

Centrally adjudicated events were prespecified and included the following: all-cause mortality, cardiovascular mortality, non-cardiovascular mortality (pulmonary, malignancy, infection, trauma, surgery, suicide, renal, other) or cardiovascular morbid events (nonfatal myocardial infarction or stroke, carotid, peripheral vascular or coronary revascularization).

For purposes of this analysis, loss of allograft function or kidney failure during the follow-up is defined as retransplantation or return to dialysis.

\section{Statistical analysis}

Baseline data were summarized using either mean and SD or median and interquartile range for continuous variables and using count and percentage for categorical variables. Global tests of equality across smoking groups were conducted using analysis of variance, the Kruskal-Wallis test and Pearson's chi-squared test, respectively. Differences in risk for clinical outcomes associated with smoking status were assessed by Kaplan-Meier curves as well as unadjusted and adjusted Cox models. Adjusted models included age, race, sex, low-density lipoprotein, systolic blood pressure and chronic kidney disease class, and all Cox models were stratified by country (the USA, Canada, Brazil). These relationships were then tested with subgroups of patients according to their diabetes status, 
and the interaction between smoking and diabetes status was assessed by likelihood ratio test. $p$-values $<0.05$ were considered significant. No adjustment was made for multiple comparisons. All analyses were conducted using STATA 14 (StataCorp LP, College Station, TX, USA).

\section{Clinical significance}

- Exactly 4110 stable kidney allograft recipients were enrolled for an average of 4 years after successful surgery. Eleven percent were currently smoking, 39\% were former smokers, 50\% never smoked.

- Current smoking was associated with $100 \%$ increase in hazard of non-cardiovascular death, 50\% increase in allograft failure and $60 \%$ increase in composite endpoint of death or allograft failure.

- Cessation of smoking is needed in kidney transplant recipients to preserve survival free of dialysis.

\section{Results}

For the 4110 stable kidney transplant recipients who were randomized in the FAVORIT trial, baseline data are shown in Table 1. Current smoking, former smoking and never smoking were noted in 451 (10.9\%), 1611 (39.2\%) and 2048 $(49.8 \%)$ patients, respectively. Body mass index was slightly lower and serum creatinine slightly higher in current smokers than in either nonsmokers or former smokers. Smokers were slightly younger than either nonsmokers or former smokers.

Table 2 shows the mortality rates through the course of this study per 100 patient-years of follow-up. There were 493 deaths over a mean of 3.8 years of follow-up. Both current and prior smoking histories were associated with significantly increased all-cause mortality over the course of follow-up. Causes of death were predominantly non-cardiovascular, adjudicated by the clinical event committee as due to infection $(n=113)$, malignancy $(n=76)$, pulmonary $(n=26)$, gastrointestinal $(n=24)$, accident $(n=15)$, renal $(n=12)$, diabetes $(n=1)$, unknown cause $(n=17)$ or suicide $(n=2)$ in origin. The incidence rates of central clinical event committee-adjudicated all-cause, cardiovascular, non-cardiovascular mortality, nonfatal cardiovascular events and kidney allograft failure (predefined as initiation of dialysis therapy or retransplantation) during study follow-up are also presented in Table 2.

Table I Demographics for 4II0 participants of the FAVORIT trial $\left.\right|^{9-11,14}$ with stable renal allografts at baseline classified by presence, type and absence of diabetes and smoking history

\begin{tabular}{|c|c|c|c|c|}
\hline & Nonsmoker $(n=2048)$ & Current smoker $(n=45 I)$ & Former smoker $(n=1611)$ & Global, $p$-value \\
\hline \multicolumn{5}{|l|}{ Diabetes category } \\
\hline No DM & I 204 (49.2) & 297 (12.1\%) & 946 (38.7\%) & 0.005 \\
\hline Type I & $78(47.0 \%)$ & $25(15.1 \%)$ & $63(38.0 \%)$ & \\
\hline Type 2 & $766(51.2 \%)$ & $129(8.6 \%)$ & $602(40.2 \%)$ & \\
\hline Age & $51 \pm 10$ & $49 \pm 8$ & $54 \pm 9$ & $<0.001$ \\
\hline Non-white & $520(25.9 \%)$ & II 5 (26.0\%) & $310(19.7 \%)$ & $<0.001$ \\
\hline \multicolumn{5}{|l|}{ Country } \\
\hline USA & 1506 (50.2\%) & 335 (II.2\%) & 1159 (38.6\%) & 0.18 \\
\hline Canada & $260(52.2 \%)$ & $52(10.4 \%)$ & $186(37.3 \%)$ & \\
\hline Brazil & $282(46.1 \%)$ & $64(10.5 \%)$ & $266(43.5 \%)$ & \\
\hline Female & 870 (56.9\%) & $150(9.8 \%)$ & $508(33.2 \%)$ & $<0.001$ \\
\hline Prevalent CVD & 317 (15.6\%) & $92(20.4 \%)$ & $4 I I(25.5 \%)$ & $<0.001$ \\
\hline HTN & 1866 (91.1\%) & $417(92.5 \%)$ & 1495 (92.8\%) & 0.16 \\
\hline Graft vintage (years) & $4.1(1.8,7.9)$ & $3.8(1.9,8.1)$ & $4.0(1.5,7.0)$ & 0.022 \\
\hline \multicolumn{5}{|l|}{ Allograft source } \\
\hline Nonliving & I I 97 (58.4\%) & 277 (6I.4\%) & 897 (55.7\%) & 0.06 \\
\hline Living & $839(41.0 \%)$ & $169(37.5 \%)$ & 697 (43.3\%) & 0.07 \\
\hline $\mathrm{BMI}$ & $29.20 \pm 6.23$ & $27.94 \pm 6.42$ & $29.48 \pm 6.16$ & $<0.00$ I \\
\hline Creatinine (mg/dL) & $1.62 \pm 0.48$ & $I .7 I \pm 0.50$ & $1.63 \pm 0.47$ & $<0.001$ \\
\hline eGFR & $49.15 \pm 16.56$ & $48.03 \pm 17.09$ & $48.50 \pm 15.44$ & 0.29 \\
\hline \multicolumn{5}{|l|}{ CKD } \\
\hline GFR $\geq 90$ & 45 (2.2\%) & $8(1.8 \%)$ & $16(1.0 \%)$ & 0.034 \\
\hline $60 \leq \mathrm{GFR}<90$ & $402(20.0 \%)$ & 85 (19.2\%) & $332(21.1 \%)$ & \\
\hline $30 \leq \mathrm{GFR}<60$ & I 384 (68.9\%) & $293(66.3 \%)$ & $106 \mid(67.5 \%)$ & \\
\hline $15 \leq$ GFR $8<30$ & 177 (8.8\%) & $56(12.7 \%)$ & 161 (10.2\%) & \\
\hline GFR $<15$ & $0(0.0 \%)$ & $0(0.0 \%)$ & I $(0.1 \%)$ & \\
\hline
\end{tabular}

Abbreviations: BMI, body mass index; CKD, chronic kidney disease; CVD, cardiovascular disease; DM, diabetes mellitus; eGFR, estimated glomerular filtration rate; FAVORIT, Folic Acid for Vascular Outcome Reduction in Transplant; GFR, glomerular filtration rate; HTN, hypertension. 
Table 2 Outcomes for 4 I 10 participants of the FAVORIT trial ${ }^{9-11,14}$ with stable renal allografts at baseline stratified by smoking history

\begin{tabular}{|c|c|c|c|}
\hline & \multicolumn{2}{|c|}{ Hazard ratios related to smoking status } & \multirow[b]{2}{*}{ Former smokers $(n=1611)$} \\
\hline & Nonsmokers $(n=2048)$ & Current smokers $(n=45 I)$ & \\
\hline \multicolumn{4}{|l|}{ All-cause mortality } \\
\hline Number and \% of participants with & $196(9.6 \%)$ & $71(15.8 \%)$ & $226(14.0 \%)$ \\
\hline events, and incidence rate per $100 \mathrm{pyr}$ & 2.4 per 100 pyr & 4.0 per 100 pyr & 3.5 per 100 pyr \\
\hline \multirow[t]{2}{*}{ Unadjusted model ${ }^{\mathrm{a}}$} & Ref. & I.7I (1.30-2.24) & $1.48(1.22-1.79)$ \\
\hline & & $<0.001$ & $<0.001$ \\
\hline \multirow[t]{2}{*}{ Adjusted model ${ }^{\mathrm{b}}$} & Ref. & $1.70(1.26-2.29)$ & $1.21(0.98-1.50)$ \\
\hline & & 0.001 & 0.08 \\
\hline \multicolumn{4}{|l|}{ Non-cardiovascular death } \\
\hline Number and \% of participants with & $98(4.8 \%)$ & $48(10.7 \%)$ & $140(8.7 \%)$ \\
\hline events, and incidence rate per $100 \mathrm{pyr}$ & 1.2 per 100 pyr & 2.7 per 100 pyr & 2.2 per $100 \mathrm{pyr}$ \\
\hline \multirow[t]{2}{*}{ Unadjusted model ${ }^{\mathrm{a}}$} & Ref. & $2.29(1.62-3.24)$ & $1.83(1.4 I-2.36)$ \\
\hline & & $<0.001$ & $<0.001$ \\
\hline \multirow[t]{2}{*}{ Adjusted model ${ }^{b}$} & Ref. & $2.39(1.62-3.5 I)$ & $1.50(1.12-2.01)$ \\
\hline & & $<0.001$ & 0.007 \\
\hline \multicolumn{4}{|l|}{ Cardiovascular death } \\
\hline Number and \% of participants with & $88(4.4 \%)$ & $23(5.1 \%)$ & $80(5.0 \%)$ \\
\hline events, and incidence rate per $100 \mathrm{pyr}$ & I.I per 100 pyr & 1.3 per $100 \mathrm{pyr}$ & 1.3 per $100 \mathrm{pyr}$ \\
\hline \multirow[t]{2}{*}{ Unadjusted model ${ }^{\mathrm{a}}$} & Ref. & $1.26(0.79-1.99)$ & $1.17(0.86-1.58)$ \\
\hline & & 0.33 & 0.32 \\
\hline \multirow[t]{2}{*}{ Adjusted model ${ }^{b}$} & Ref. & $1.20(0.73-1.97)$ & $0.97(0.69-1.35)$ \\
\hline & & 0.48 & 0.84 \\
\hline \multicolumn{4}{|l|}{ Cardiovascular events (adjudicated) } \\
\hline Number and \% of participants with & $252(12.5 \%)$ & $73(16.3 \%)$ & $259(16.3 \%)$ \\
\hline events, and incidence rate per $100 \mathrm{pyr}$ & 3.3 per 100 pyr & 4.5 per 100 pyr & 4.3 per $100 \mathrm{pyr}$ \\
\hline \multirow{2}{*}{ Unadjusted model ${ }^{\mathrm{a}}$} & Ref. & $1.38(1.07-1.80)$ & $1.35(1.13-1.60)$ \\
\hline & & 0.02 & 0.001 \\
\hline \multirow[t]{2}{*}{ Adjusted model ${ }^{b}$} & Ref. & $1.40(1.06-1.86)$ & $1.17(0.96-1.42)$ \\
\hline & & 0.02 & 0.12 \\
\hline \multicolumn{4}{|l|}{ Renal allograft failure } \\
\hline Number and \% of participants with & $157(7.8 \%)$ & $58(13.1 \%)$ & $128(8.1 \%)$ \\
\hline events, and incidence rate per $100 \mathrm{pyr}$ & 2.0 per 100 pyr & 3.5 per 100 pyr & 2.1 per 100 pyr \\
\hline \multirow[t]{2}{*}{ Unadjusted model ${ }^{\mathrm{a}}$} & Ref. & $1.80(1.33-2.43)$ & $1.05(0.83-1.33)$ \\
\hline & & $<0.001$ & 0.67 \\
\hline \multirow[t]{2}{*}{ Adjusted model ${ }^{b}$} & Ref. & $1.49(1.06-2.01)$ & $1.15(0.88-1.5 \mathrm{I})$ \\
\hline & & 0.02 & 0.30 \\
\hline \multicolumn{4}{|c|}{ Allograft failure OR all-cause mortality } \\
\hline Number and \% of participants with & $320(15.9 \%)$ & $112(25.2 \%)$ & $308(19.5 \%)$ \\
\hline events, and incidence rate per $100 \mathrm{pyr}$ & 4.0 per 100 pyr & 6.8 per 100 pyr & 5.0 per 100 pyr \\
\hline \multirow[t]{2}{*}{ Unadjusted model ${ }^{\mathrm{a}}$} & Ref. & $1.71(1.38-2.12)$ & $1.24(1.06-1.45)$ \\
\hline & & $<0.001$ & 0.008 \\
\hline \multirow[t]{2}{*}{ Adjusted model ${ }^{b}$} & Ref. & $1.61(1.27-2.04)$ & $1.15(0.96-1.37)$ \\
\hline & & $<0.001$ & 0.13 \\
\hline
\end{tabular}

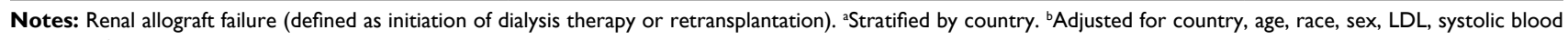
pressure, CKD class stage.

Abbreviations: CKD, chronic kidney disease; FAVORIT, Folic Acid for Vascular Outcome Reduction in Transplant; LDL, low-density lipoprotein; pyr, person-years.

Although current smoking was not associated with a significant increase in cardiovascular death, it was associated with a statistically significant increase in cardiovascular events.

Kidney allograft failure and the composite of allograft failure plus all-cause mortality were associated with current, but not former smoking. Current smoking significantly increased the risk of allograft failure during the study by $50 \%$ and the hazard of the composite end-point of either death or allograft failure by $60 \%$, when compared either to nonsmoking or former smoking.
Figure 1 illustrates the patient survival curves during FAVORIT and the impact of current smoking at baseline, when compared to former smoking and never smoking among all kidney transplant recipients (Figure 1A). It should be noted that whereas there is a difference in results between current, former and prior smokers in the nonliving donor recipients (Figure 1B), this was not demonstrated in the recipients of live-related donor allografts in whom statistically significant difference was not achieved (Figure 1C). Mortality is this overall study was predominantly from non-cardiovascular 
A

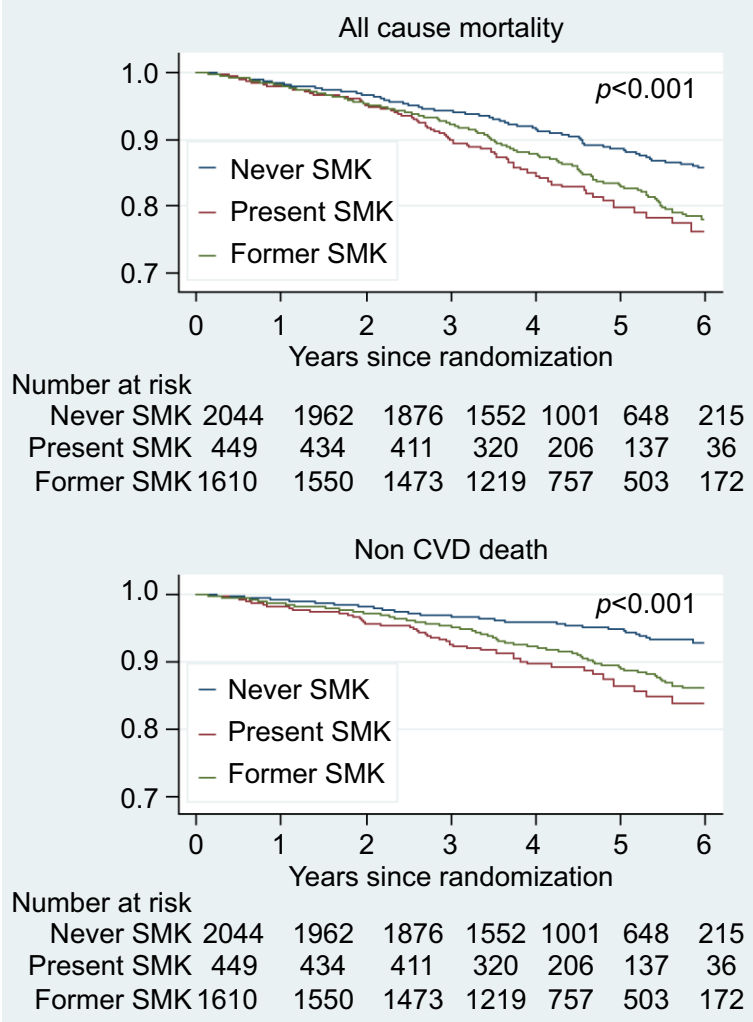

B

All cause mortality

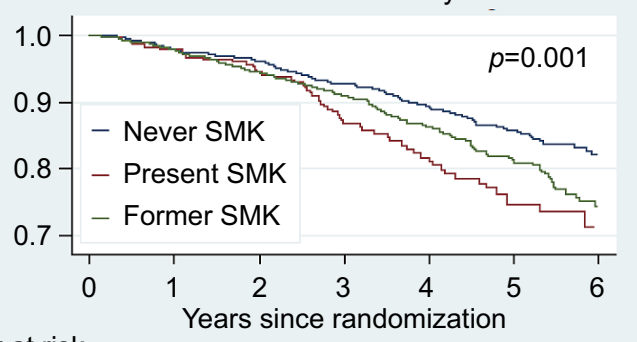

Number at risk

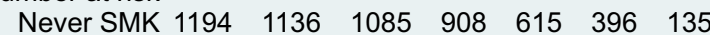

$\begin{array}{llllllll}\text { Present SMK } & 275 & 265 & 249 & 194 & 132 & 86 & 19\end{array}$

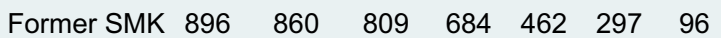

CVD death

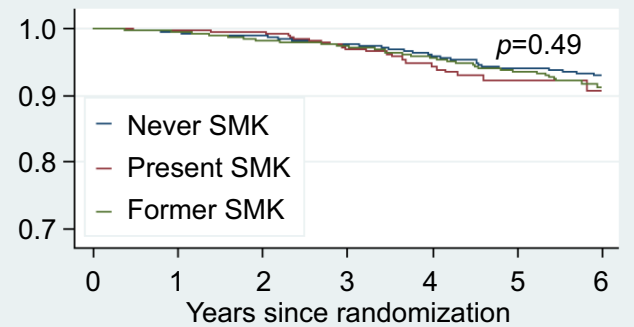

Number at risk

Never SMK $2020 \quad 1942 \quad 1850 \quad 1533 \quad 983 \quad 635 \quad 212$

$\begin{array}{llllllll}\text { Present SMK } & 448 & 430 & 400 & 312 & 198 & 135 & 36\end{array}$

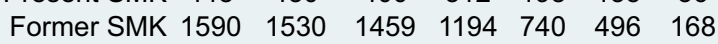

Non CVD death

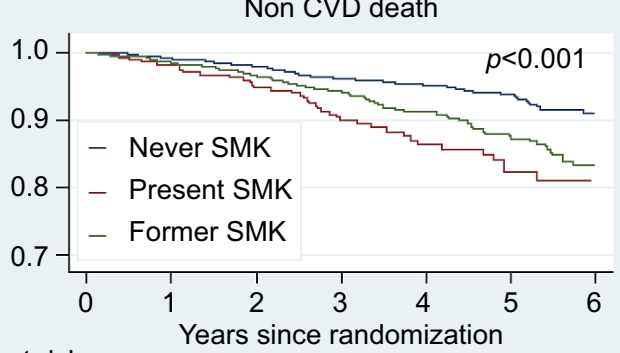

Number at risk

Never SMK $1194 \quad 1136 \quad 1085 \quad 908 \quad 615 \quad 396 \quad 135$

$\begin{array}{llllllll}\text { Present SMK } & 275 & 265 & 249 & 194 & 132 & 86 & 19\end{array}$

$\begin{array}{llllllll}\text { Former SMK } & 896 & 860 & 809 & 684 & 462 & 297 & 96\end{array}$

Figure I (Continued)

Number at risk

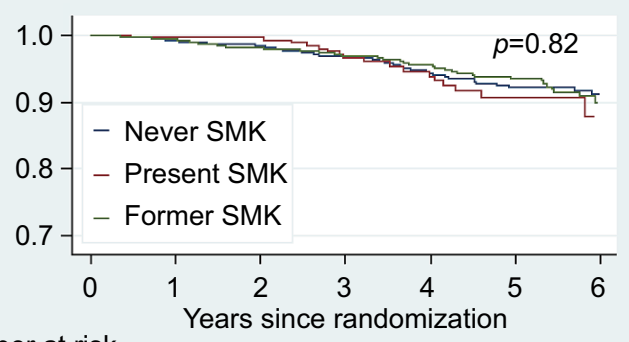

$\begin{array}{llllllll}\text { Never SMK } & 1178 & 1121 & 1073 & 900 & 604 & 386 & 132\end{array}$

$\begin{array}{llllllll}\text { Present SMK } & 275 & 262 & 245 & 190 & 125 & 85 & 19\end{array}$

$\begin{array}{llllllll}\text { Former SMK } & 882 & 847 & 801 & 667 & 450 & 293 & 93\end{array}$ 
C

All cause mortality

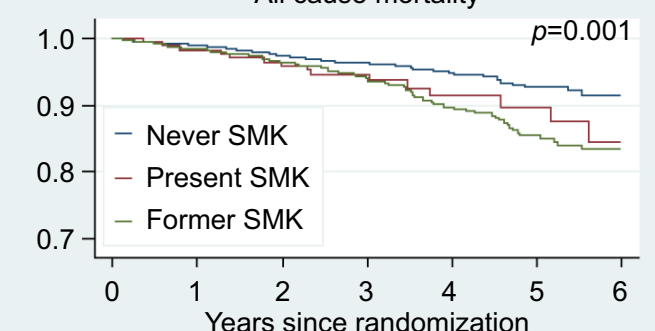

Number at risk

$\begin{array}{llllllll}\text { Never SMK } & 838 & 815 & 780 & 633 & 377 & 246 & 80\end{array}$

$\begin{array}{llllllll}\text { Present SMK } & 169 & 164 & 157 & 121 & 70 & 47 & 17\end{array}$

$\begin{array}{llllllll}\text { Former SMK } & 697 & 674 & 649 & 522 & 285 & 198 & 76\end{array}$

\section{CVD death}

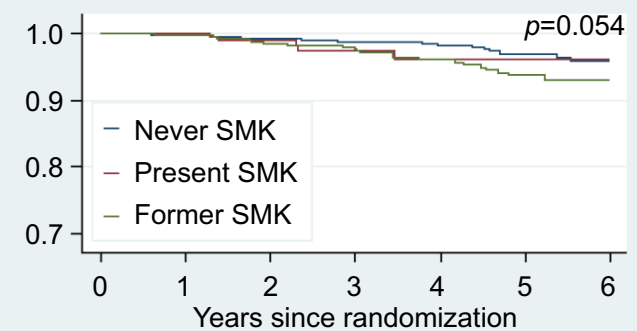

Number at risk

$\begin{array}{llllllll}\text { Never SMK } & 831 & 810 & 766 & 622 & 370 & 243 & 80\end{array}$

$\begin{array}{llllllll}\text { Present SMK } & 168 & 163 & 150 & 117 & 69 & 46 & 17\end{array}$

$\begin{array}{llllllll}\text { Former SMK } & 692 & 668 & 643 & 514 & 280 & 195 & 75\end{array}$

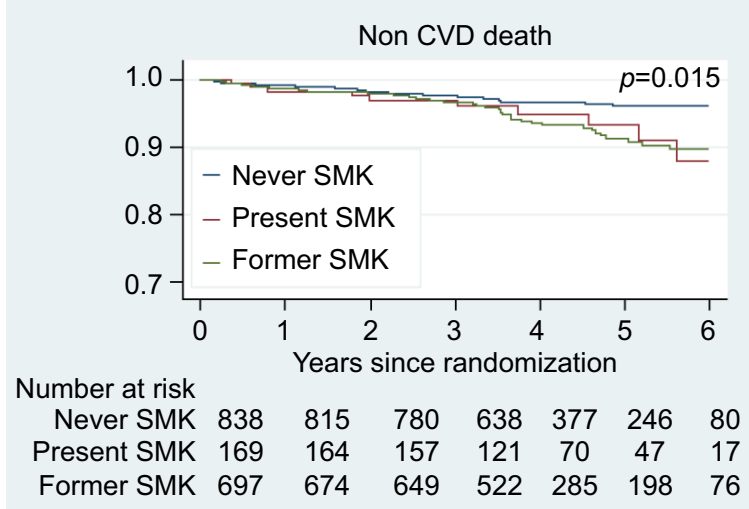

Figure I Patient survival outcomes based upon smoking history (all-cause mortality, CV mortality, non-CV mortality).

Notes: (A) All transplant recipients. (B) Nonliving donor allograft recipients (cadaver). (C) Living donor allograft recipients (living).

Abbreviations: $\mathrm{CV}$, cardiovascular; CVD, cardiovascular disease.

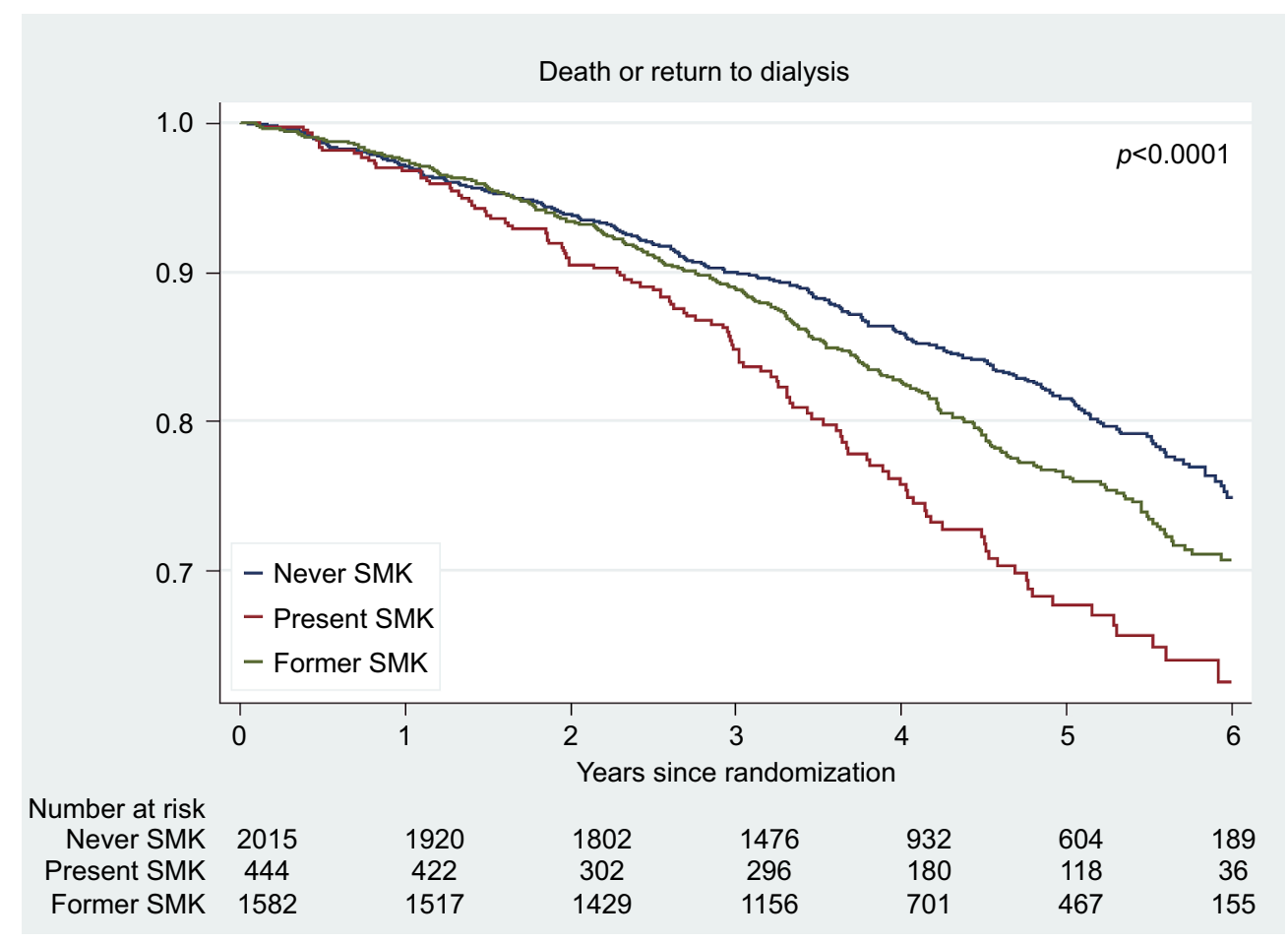

Figure 2 Composite of death or return to dialysis based upon smoking status. 
causes, as has previously been reported. Figure 2 focuses on the effect of current and former smoking on graft survival rates (death censored). For the composite outcome of death or return to dialysis, there were significant differences among the three groups defined by smoking history irrespective of the source of the allograft.

Table 3 shows the relationship between event rates and presence or type of diabetes based upon the absence or presence and the type of diabetes as well as the smoking history at entry into this study. Among both type 2 diabetic and nondiabetic kidney transplant recipients, current smoking was associated with an increased hazard of non-cardiovascular events to a greater degree than the history of never smoking. A statistical interaction with diabetes was not demonstrated. The number of type 1 diabetic patients in this study was likely too small to generate statistically significant differences in the context of this study.

\section{Discussion}

Multiple observational studies have demonstrated smokingrelated excess of cardiovascular nonfatal and fatal events in populations at relatively low risk. This risk increases in the presence of comorbidities that include organ damage (renal, cardiovascular, respiratory, neurologic), obesity, hyperlipidemia, diabetes and hypertension. In this post hoc analysis of the FAVORIT trial, which was designed to test the hypothesis that lowering homocysteine (a biomarker associated with excess cardiovascular risk) with folate and B12 would decrease cardiovascular events in kidney transplant recipients, we have attempted to decipher an effect of smoking.

Several studies have suggested an increased non-cardiovascular death rate in a transplant population well screened for cardiovascular risk factors. ${ }^{12,13}$ Such non-cardiovascular event reports include increased malignancy and increased infection-related complications/mortality. ${ }^{14}$ The current FAVORIT study confirms reports for kidney transplant recipients and liver transplant recipients in two European and one North American center with $>700$ recipients. ${ }^{15,16-18}$

The cause of death for the majority of kidney transplant recipients is non-cardiovascular, due to extensive screening of recipients prior to surgery with cardiovascular events that are usually survived, as was observed in this study. ${ }^{19,20}$ The current study confirms prior observations of a statistically significant excess risk of (centrally adjudicated) cardiovascular events in current smokers when compared to nonsmokers in trial cohorts in three countries. Interestingly, deaths adjudicated as cardiovascular were not significantly increased among smokers compared to nonsmokers in our study. Decreased survival rates among current smokers were driven by an excess of infection-related deaths. We also noted that the hazard rate for diabetic patients suffering an infection-related death was much higher than that for nondiabetic immunosuppressed individuals. ${ }^{21,22}$

Our study adds to the scientific literature the observation that careful adjudication of events can discern that the effect of smoking on all-cause mortality of kidney transplant recipients is mediated by an excess of non-cardiovascular deaths (primarily infection related more than malignancy). Further analysis of the reasons for this excess mortality deserves additional study. In the meantime, aggressive collection of data from patients who are vaping or chronically smoking marijuana is needed. Insistence upon smoking cessation for preservation of graft function and patient survival appears appropriate.

Impact of smoking on solid organ transplantation has been studied for three decades. For kidney transplantation, definitions of outcomes have included hazard ratio for cardiovascular events associated with smoking ${ }^{21,22}$ and hazard ratios for cardiovascular mortality. ${ }^{23-32}$ Two previous studies focused on the incidence of first cardiovascular events ${ }^{32}$ or the number of cardiovascular events..$^{20}$ Each of these studies demonstrated significance in impact of smoking with hazard ratios all higher than 1.4. A single study of kidney transplantation did not demonstrate a statistically significant impact of smoking on cardiovascular health. ${ }^{33}$ In this study of well-screened transplant recipients, we did find an increased hazard ratio for current smoking with regard to cardiovascular event. We did not find an increased hazard of cardiovascular death associated with current smoking.

For liver transplantation, one study demonstrated a significant impact of smoking on the incidence of cardiovascular events ${ }^{16}$ and a single study demonstrated a significant impact of smoking on cardiovascular mortality. ${ }^{17}$ A single study of liver transplantation did not demonstrate a statistically significant impact of smoking on cardiovascular health. ${ }^{18}$

Our results are in agreement with the findings of others in that there is up to a twofold hazard of death associated with smoking. In addition, the hazard ratio reported for continued smoking upon allograft loss of function has been reported to range from 1.4 to 8.0. Most reports impute excess mortality to the effect of smoking on cardiovascular incidents; however, events are not centrally adjudicated and a large fraction of them are assessed as being of undetermined etiology. In addition, one analysis in the USA Renal Data System assigned a nonresponse to the question of smoking status to the nonsmoking group, rendering the information somewhat doubtful. ${ }^{21,22}$ 


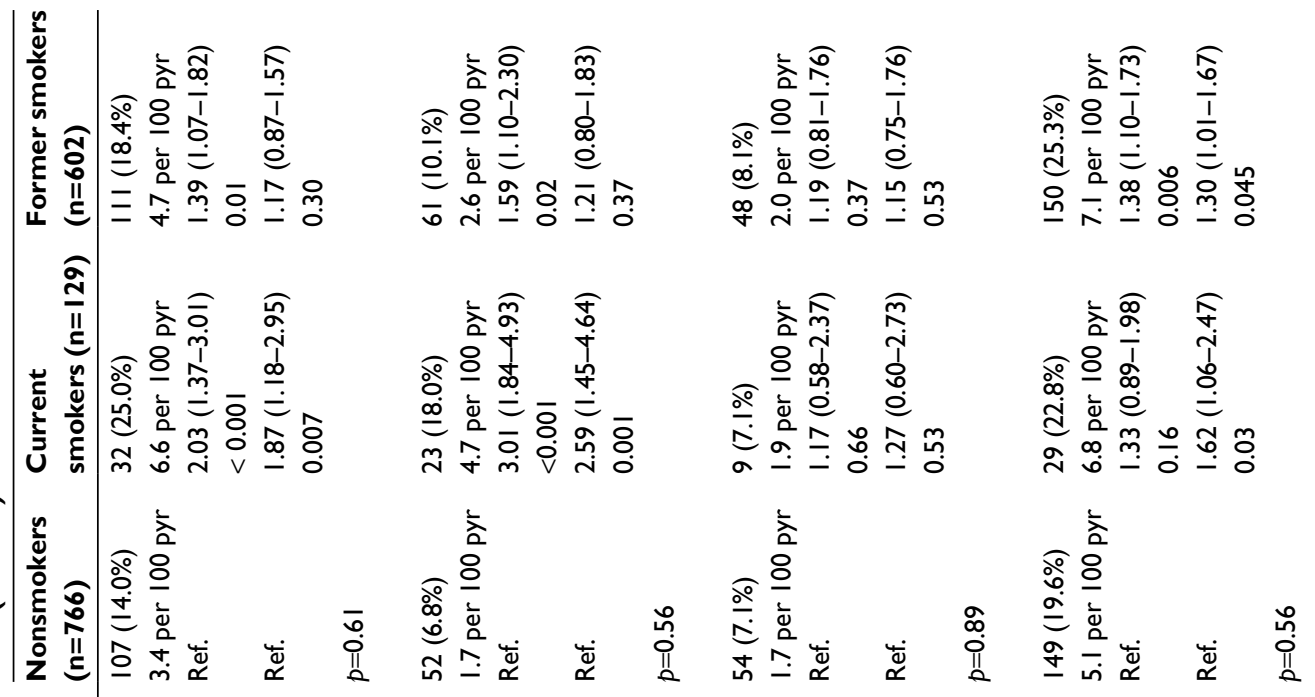

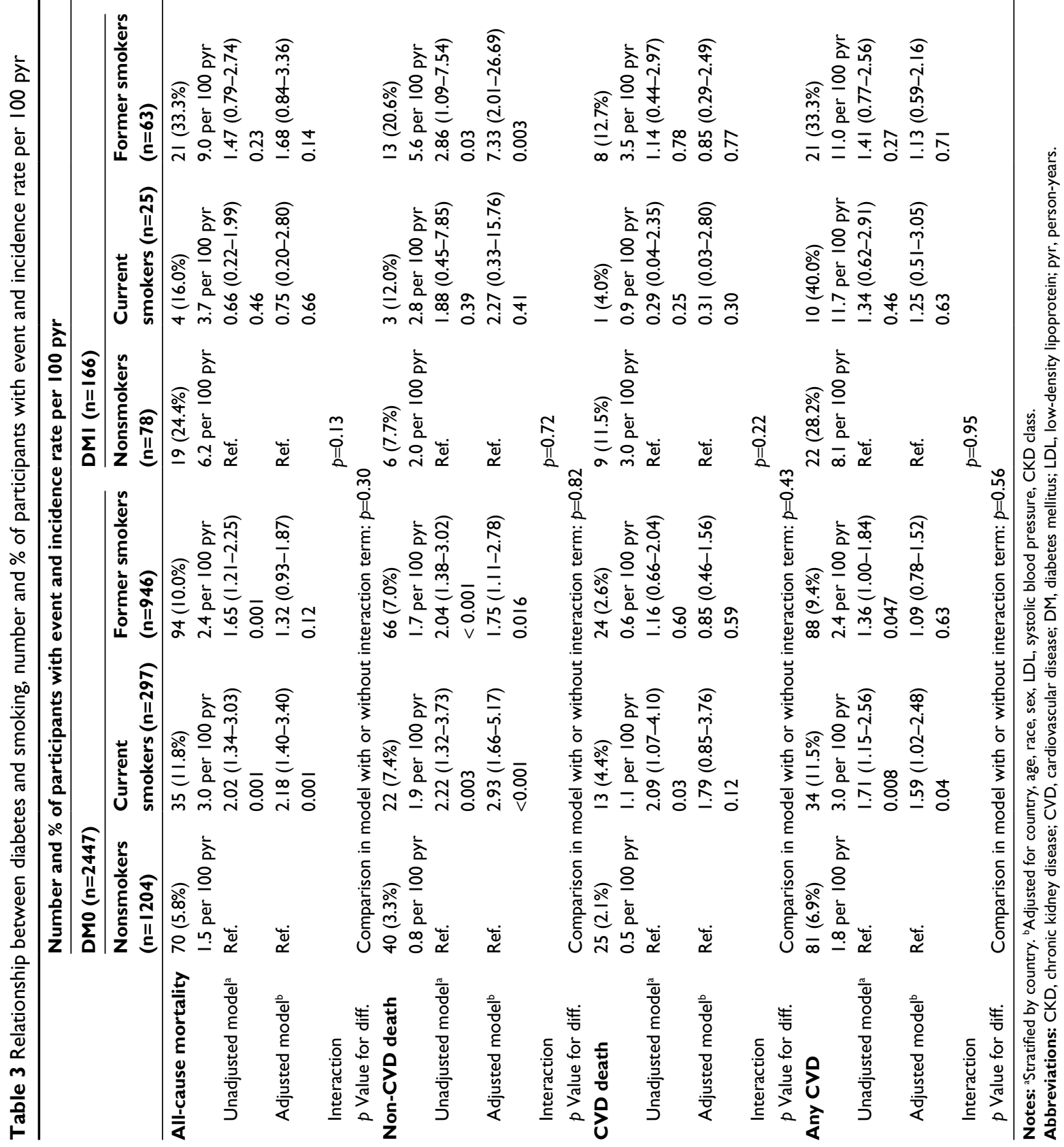


Efforts to reduce smoking in transplant populations may provide benefits unrelated to lowering of cardiovascular events. There are sufficient studies to suggest that phagocytosis of invading pathogens by macrophages and cellular signaling are interfered with at the alveolar level by cigarette smoking. ${ }^{34}$ Studies to determine whether smoking depresses immunity further in the presence than in the absence of immunomodulators would be worthwhile. Long-term kidney transplant results may be improved by attention to smoking cessation.

Smoking contributes an excess risk of return to dialysis or retransplantation. Continued smoking in our patient cohort was associated with $>100 \%$ increased risk of death and a $50 \%$ greater risk of graft loss, a risk not seen in our former smokers. Sufficient data regarding the relationship of smoking to allograft loss are not always included in recent reviews, ${ }^{35,36}$ and current guidelines do not consider current smoking a relative contraindication to kidney transplantation, though this restriction has been identified for transplant of liver, heart and lung. ${ }^{19,36}$ The continued expansion of dialysis to populations with a high prevalence of smoking may eventually require reconsideration of a proscription of smoking in potential transplant recipients.

\section{Limitations}

Nicotine levels were not measured. Smoking status was self-identified by enrollees at the baseline visit. Dosage of exposure cannot be measured as the duration and extent of tobacco use were not available. No meaningful observation can be made regarding the effects of second-hand smoke exposure or pollution on the results of this study.

The choice of the Americas, a region in which prevalence of smoking is somewhat less and prevalence of diabetes is somewhat higher than other geographic regions, may not reflect all transplant recipients worldwide. It is likely that worldwide prevalence of current smoking among kidney transplant recipients is understated. In the FAVORIT study, the default was to consider deaths to be from cardiovascular causes in case of any doubt. Thus, impact of non-cardiovascular causes may actually be understated. Despite concentration and overexpression of cardiovascular issues in this protocol, there were too few cardiovascular deaths to demonstrate an effect of smoking.

Generalization of our observed hazard ratios for noncardiovascular death and transplant graft failure to the overall transplant population may actually understate the impact of smoking in populations in which the prevalence of current cigarette use is higher. That said, we can conceive of no hypothesis to support a negative consequence of promoting smoking cessation with an aim toward improved transplant survival.

\section{Conclusion}

Among kidney transplant recipients, continuation of smoking was observed in $11 \%$ of patients in the international FAVORIT trial. We discerned an adverse relationship between both former smoking and continued smoking upon all-cause mortality in this population. Although there was an effect of smoking on cardiovascular event rate, fully two-thirds of kidney transplant patients died from causes not considered to be cardiovascular. Current smoking was associated with a $50 \%$ increase in the risk of allograft failure and a $60 \%$ increase in the risk of the composite of death and allograft failure. Given the adverse effects of this modifiable risk factor, current smoking should be considered a relative contraindication to the transplant of limited resourced organs.

\section{Disclosure}

All authors declare an absence of conflicts of interest relevant to this NIH funded study.

\section{References}

1. Maurer JR, Frost AE, Estenne M, Higenbottam T, Glanville AR. International guidelines for the selection of lung transplant candidates. The International Society for Heart and Lung Transplantation, the American Thoracic Society, the American Society of Transplant Physicians, the European Respiratory Society. Transplantation. 1998;66(7):951-956.

2. Orens JB, Estenne M, Arcasoy S, et al; Pulmonary Scientific Council of the International Society for Heart and Lung Transplantation. International guidelines for the selection of lung transplant candidates: 2006 update-a consensus report from the Pulmonary Scientific Council of the International Society for Heart and Lung Transplantation. J Heart Lung Transplant. 2006;25(7):745-755.

3. Mehra MR, Kobashigawa J, Starling R, et al. Listing criteria for heart transplantation: International Society for Heart and Lung Transplantation guidelines for the care of cardiac transplant candidates-2006. J Heart Lung Transplant. 2006;25(9):1024-1042.

4. Martin P, DiMartini A, Feng S, Brown R Jr, Fallon M. Evaluation for liver transplantation in adults: 2013 practice guideline by the American Association for the Study of Liver Diseases and the American Society of Transplantation. Hepatology. 2014;59(3):1144-1165.

5. Dudley C, Harden P. Renal association clinical practice guideline on the assessment of the potential kidney transplant recipient. Nephron Clin Pract. 2011;118(Suppl 1):c209-c224.

6. Abramowicz D, Cochat P, Claas FH, et al. European renal best practice guideline on kidney donor and recipient evaluation and perioperative care. Nephrol Dial Transplant. 2015;30(11):1790-1797.

7. Schneider A, Jardine AG, Schneider MP, et al. Determinants of cardiovascular risk in haemodialysis patients: post hoc analyses of the AURORA study. Am J Nephrol. 2013;37(2):144-151.

8. Leggat JE Jr, Orzol SM, Hulbert-Shearon TE, et al. Noncompliance in hemodialysis: predictors and survival analysis. Am J Kidney Dis. 1998;32(1):139-145.

9. Bostom AG, Carpenter MA, Kusek JW, et al; FAVORIT Investigators. Rationale and design of the Folic Acid for Vascular Outcome Reduction In Transplantation (FAVORIT) trial. Am Heart J. 2006;152(3):448e1-e7. 
10. Bostom AG, Carpenter MA, Hunsicker L, et al; FAVORIT Study Investigators. Baseline characteristics of participants in the Folic Acid for Vascular Outcome Reduction in Transplantation (FAVORIT) Trial. Am J Kidney Dis. 2009;53(1):121-128.

11. Bostom AG, Carpenter MA, Kusek JW, et al. Homocysteine-lowering and cardiovascular disease outcomes in kidney transplant recipients: primary results from the Folic Acid for Vascular Outcome Reduction in Transplantation Trial. Circulation. 2011;123(16):1763-1770.

12. Maamoun HA, Soliman AR, Fathy A, Elkhatib M, Shaheen N. Diabetes mellitus as predictor of patient and graft survival after kidney transplantation. Transplant Proc. 2013;45(9):3245-3248.

13. Hayer MK, Farrugia D, Begaj I, Ray D, Sharif A. Infection-related mortality is higher for kidney allograft recipients with pretransplant diabetes mellitus. Diabetologia. 2014;57(3):554-561.

14. Weinrauch LA, D'Elia JA, Weir MR, et al. Infection and malignancy outweigh cardiovascular mortality in kidney transplant recipients: post Hoc analysis of the FAVORIT trial. Am J Med. 2018;131(2): 165-172.

15. Cosio FG, Falkenhain ME, Pesavento TE, et al. Patient survival after renal transplantation: II. The impact of smoking. Clin Transplant. 1999;13(4):336-341.

16. Pungpapong S, Manzarbeitia C, Ortiz J, et al. Cigarette smoking is associated with an increased incidence of vascular complications after liver transplantation. Liver Transpl. 2002;8(7):582-587.

17. Leithead JA, Ferguson JW, Hayes PC. Smoking-related morbidity and mortality following liver transplantation. Liver Transpl. 2008;14(8):1159-1164.

18. Van der Heide F, Dijkstra G, Porte RJ, Kleibeuker JH, Haagsma EB. Smoking behavior in liver transplant recipients. Liver Transpl. 2009;15(6):648-655.

19. Weinrauch LA, D'Elia JA, Monaco AP, et al. Preoperative evaluation for diabetic renal transplantation: the impact of clinical, laboratory, and echocardiographic evaluation on patient and allograft survival. Am J Med. 1992;93(1):19-28.

20. West JC, Napoliello DA, Costello JM, et al. Preoperative dobutamine stress echocardiography versus cardiac arteriography for risk assessment prior to renal transplantation. Transpl Int. 2000;13(Suppl 1):S27-S30.

21. Hurst FP, Altireri M, Patel PP, et al. Effect of smoking on transplant outcomes: analysis of the United States Renal Data System. Transplantation. 2011;92(10):1101-1107.

22. Hecht EM, Arheart KL, Hennekens CH, Hlaing WM. Interrelation of Cadmium, smoking, and cardiovascular disease (from the National Health and Nutrition Examination Survey). Am J Cardio. 2016;118(2):204-209.
23. Arend SM, Mallat MJ, Westendorp RJ, van der Woude FJ, van Es LA. Patient survival after renal transplantation; more than 25 years followup. Nephrol Dial Transplant. 1997;12(8):1672-1679.

24. Cosio FG, Alimir A, Yim S, et al. Patient survival after renal transplantation: I. The impact of dialysis pre-transplant. Kidney Int. 1998;53(3): $767-772$.

25. Doyle SE, Matas AJ, Gillingham K, Rosenberg ME. Predicting clinical outcome in the elderly renal transplant recipient. Kidney Int. 2000;57(5):2144-2150.

26. Kasiske BL, Chakkera HA, Roel J. Explained and unexplained ischemic heart disease risk after renal transplantation. J Am Soc Nephrol. 2000;11(9):1735-1743.

27. Woo YM, McLean D, Kavanagh D, et al. The influence of pre-operative electrocardiographic abnormalities and cardiovascular risk factors on patient and graft survival after renal transplantation. $J$ Nephrol. 2002;15(4):380-386.

28. de Mattos AM, Prather J, Olyaei AJ, et al. Cardiovascular events following renal transplantation: role of traditional and transplant-specific risk factors. Kidney Int. 2006;70(4):757-764.

29. Nogueira JM, Haririan A, Jacobs SC, Cooper M, Weir MR. Cigarette smoking, kidney function, and mortality after live donor kidney transplant. Am J Kidney Dis. 2010;55(5):907-915.

30. Agarwal PK, Hellemons ME, Zelle DM, et al. Smoking is a risk factor for graft failure and mortality after renal transplantation. Am J Nephrol. 2011;34(1):26-31.

31. Corbett C, Armstrong MJ, Neuberger J. Tobacco smoking and solid organ transplantation. Transplantation. 2012;94(10):979-987.

32. Kasiske BL. Risk factors for accelerated atherosclerosis in renal transplant recipients. Am J Med. 1988;84(6):985-992.

33. Israni AK, Snyder JJ, Skeans MA, et al; PORT Investigators. Predicting coronary heart disease after kidney transplantation: patient outcomes in renal transplantation (PORT) study. Am J Transplant. 2010;10(2): 338-353.

34. Karavitis J, Kovacs EJ. Macrophage phagocytosis: effects of environmental pollutants, alcohol, cigarette smoke, and other external factors. J Leukoc Biol. 2011;90(6):1065-1078.

35. Nankivell BJ, Kuypers DRJ. Organ transplantation 3: diagnosis and prevention of chronic kidney allograft loss. Lancet. 2011;378(9800): 1428-1435.

36. Duerinckx N, Burkhalter H, Engberg SJ, et al; B-SERIOUS consortium. Correlates and outcomes of posttransplant smoking in solid organ transplant recipients: a systematic literature review and meta-analysis. Transplantation. 2016;100(11):2252-2263.

\section{Publish your work in this journal}

The International Journal of Nephrology and Renovascular Disease is an international, peer-reviewed open access journal focusing on the pathophysiology of the kidney and vascular supply. Epidemiology, screening, diagnosis, and treatment interventions are covered as well as basic science, biochemical and immunological studies. The manuscript management system is completely online and includes a very quick and fair peer-review system, which is all easy to use. Visit http://www. dovepress.com/testimonials.php to read real quotes from published authors. 